\title{
Is Galectin-3 a Prognosticator of Severity and Clinical Outcomes of Pulmonary Artery Hypertension?
}

\author{
Alexander Berezin* \\ Consultant of Therapeutic Unit, Internal Medicine Department, State Medical University for Zaporozhye, 26, \\ Mayakovsky Av., Zaporozhye, Ukraine
}

*Corresponding Author: Alexander Berezin, Consultant of Therapeutic Unit, Internal Medicine Department, State Medical University for Zaporozhye, 26, Mayakovsky av., Zaporozhye, Ukraine, Email: aeberezin@gmail.com

\begin{abstract}
Pulmonary arterial hypertension (PAH) is multifactorial disadptive disease with poor clinical outcomes associated with increased pulmonary artery pressure resulting in primary small-to-moderate pulmonary artery remodeling. Numerous factors, including smooth muscle cell proliferation, vasospasm, vascular fibrosis and occlusion, direct vascular injury and inflammation, impaired repair of vasculature, are involved in the pathogenesis of PAH. It has been suggested that galectin-3 as biomarker of excessive fibrosis and inflammation can be useful to predict severity and prognosis in patient with PAH. The short communication is reported that elevated Gal-3 levels were found in majority patients with PAH depending on clinical status and of the disease. Although elevated Gal-3 levels were associated with a higher risk of allcause mortality, cardiovascular mortality, and right ventricle heart failure, the value of this biomarker in PAH patients at high risk stratification is uncertain and requires to be investigated in large clinical trials.
\end{abstract}

Keywords: pulmonary artery hypertension; galectin-3; stratification; risk; biomarkers.

\section{SHORT COMMUNICATION}

Pulmonary arterial hypertension (PAH) is a steadily progressive maladaptive disease with potentially fatal consequences that has been demonstrated increasing prevalence worldwide [1]. Nature evolution of PAH closely related to vascular remodeling and endothelial dysfunction that lead to obstruction of small-to-moderate pulmonary arteries, resulting in increased pulmonary artery pressures and pulmonary vascular resistance associated with uncoupling oxygen supply and blood saturation, hypoxia, right ventricle heart failure and multi organ insufficiency [2,3]. There were found numerous factors, which contributed to several faces of the PAH including smooth muscle cell proliferation, vasospasm, vascular fibrosis and occlusion, direct vascular injury and inflammation, impaired repair of vasculature [4]. All these factors corresponding to imbalance of vasodilators (nitric oxide - NO), and prostacyclin) and vasoconstrictors (endothelin-1 - ET-1, thromboxane A2) are crucial for clinical presentation, severity and prognosis of the disease [5]. In fact, dysregulation these factors via increased oxidase (NADPH oxidase family, xanthine and aldehyde oxidases) activity and bone morphogenetic protein receptor-2 signaling mechanism produce reactive oxygen species (superoxide, hydrogen peroxide, peroxynitrite) that disrupt canonic NO synthase pathway, lead to mitochondrial dysfunction and inflammation, potentiate proliferative response of the vasculature cells, mediate thickness and fibrosis of pulmonary artery vasculature $[6,7]$. In this context, excessive inflammation and fibrosis as core players in pathogenesis of PAH corresponding to severity and prognosis of the disease.

Galectin-3 (Gal-3) is beta-galactoside binding lectin that is synthesized and secreted by inflammatory cytokine-activated macrophages / mononuclears [8]. Gal-3 was found a useful biomarker with high predictive importance in heart failure risk stratification [9]. Previous studies have shown that Gal-3 was up-regulated in adventitia of pulmonary arteries of hypoxiainduced PAH and it regulated the proliferation, differentiation, and accumulation of extracellular matrix by synthesis of collagen and other fibrotic components [10]. Gal-3 exhibited profibrotic effects interacting of platelet-derived growth factor [11], transforming growth factorbeta-1 (TGF- $\beta 1$ ), matrix metalloproteinase-9 
(MMP-9) [12] and NADPH oxidase 4 [13]. Interestingly, TGF- $\beta 1$ was able to promote the expression of Gal-3 and its translocation, while blockage of STAT3 suppressed the expression of Gal-3 induced by TGF- $\beta 1$ [13]. Thus, TGF$\beta 1$-dependent vascular fibrosis is mediated by Gal-3 / MMP-9 / STAT3 signaling cascade. Additionally, an inhibition of $\mathrm{Gal}^{-3}$ led to reduced hypoxia- induced inflammatory response in human pulmonary arterial endothelial cells and human pulmonary arterial smooth muscle cells [14]. This effect associated with suppressed realizing of tumor necrosis factor-alpha and interleukin-1, reduced expression of intercellular adhesion molecule- 1 and switching phenotype of human pulmonary arterial smooth muscle cells from a "contractile" to a "synthetic" [14].

Therefore, Gal-3 markedly triggers proliferation and differentiation of smooth muscle cells of vasculature in tandem with aldosterone increasing expression of vascular cell adhesion molecule 1 (VCAM-1) and interleukin-12: a cytokine with pro-inflammatory and antiangiogenic activity [15]. There is evidence that both Gal-3 and aldosterone failed functional capabilities of resident cells including endothelial progenitor cells, which are a component of endogenous vascular repair system [16]. Moreover, number of circulating EPCs with pro-angiogenic phenotypes inversely associated with Gal-3 levels and predicts endothelial dysfunction [17].

There was significant correlation between Gal-3 levels in PAH individuals with mean pulmonary artery pressure and right ventricular dysfunction, but this association persisted after adjustment for $\mathrm{CV}$ risk factors and severity of inflammation [18]. Although elevated Gal-3 levels were associated with a higher risk of allcause mortality, CV mortality, and heart failure [19], the role of Gal-3 in PAH patients at high risk stratification is uncertain. However, the Gal-3 could be prognosticator and possible therapeutic target for individuals with PAH [20].

In conclusion, elevated Gal-3 levels were found in majority patients with PAH depending on clinical status and of the disease. Estimating of prognosis, risk stratification and choosing of the most effective therapy in PAH might correspond to serial measures of Gal-3. In addition to conventional findings including NYHA functional class, hemodynamic features and risk scoring based on clinical criteria, the analysis of Gal-3 in peripheral blood can be useful to evaluate disease severity and medical care responses.

\section{REFERENCES}

[1] Lai YC, Potoka KC, Champion HC, Mora AL, Gladwin MT. Pulmonary arterial hypertension: the clinical syndrome. Circ Res. 2014; 115(1): 115-30.

[2] Galiè N, Humbert M, Vachiery JL, Gibbs S, Lang I, Torbicki A, et al; ESC Scientific Document Group. 2015 ESC/ERS Guidelines for the diagnosis and treatment of pulmonary hypertension: the joint task force for the diagnosis and treatment of pulmonary hypertension of the European Society of Cardiology (ESC) and the European Respiratory Society (ERS): Endorsed by: Association for European Paediatric and Congenital Cardiology (AEPC), International Society for Heart and Lung Transplantation (ISHLT) Eur Heart J. 2015;46(4):903-975

[3] Hoeper MM, Bogaard HJ, Condliffe R, Frantz R, Khanna D, Kurzyna M, et al. Definitions and diagnosis of pulmonary hypertension. $\mathrm{J}$ Am Coll Cardiol. 2013; 62(25 Suppl):D42-50.

[4] Yu J, Taylor L, Wilson J, Comhair S, Erzurum S, Polgar P. Altered expression and signal transduction of endothelin-1 receptors in heritable and idiopathic pulmonary arterial hypertension. J Cell Physiol. 2013; 228(2): 322-9.

[5] Sobolewski A, Rudarakanchana N, Upton PD, Yang J, Crilley TK, Trembath RC, et al. Failure of bone morphogenetic protein receptor trafficking in pulmonary arterial hypertension: Potential for rescue. Human Mol Genetics. 2008;17:3180-3190

[6] Bowers R, Cool C, Murphy RC, Tuder RM, Hopken MW, Flores SC, et al. Oxidative stress in severe pulmonary hypertension. Am. J. Respir. Crit. Care Med. 2004; 169, 764-769.

[7] Bryant AJ, Carrick RP, McConaha ME, Jones BR, Shay SD, Moore CS, et al. Endothelial HIF signaling regulates pulmonary fibrosisassociated pulmonary hypertension. Am. J. Physiol. Lung Cell. Mol. Physiol. 2016; 310, L249-L262

[8] Vasta G. R. Galectins as pattern recognition receptors: structure, function, and evolution. Advances in Experimental Medicine and Biology. 2012; 946: 21-36.

[9] Gehlken C, Suthahar N, Meijers WC, de Boer RA. Galectin-3 in Heart Failure: An Update of the Last 3 Years. Heart Fail Clin. 2018; 14(1): 75-92.

[10] Luo H, Liu B, Zhao L, He J, Li T, Zha L, et al. Galectin-3 mediates pulmonary vascular remodeling in hypoxia-induced pulmonary arterial hypertension. J Am Soc Hypertens. 2017; 11(10):673-683.e3. 
[11] Guo S, Feng Z. Galectin-3 mediates the effect of PDGF on pulmonary arterial hypertension. Int J Clin Exp Med. 2015; 8(9): 15302-7.

[12] Wang X, Wang Y, Zhang J, Guan X, Chen M, Li Y, Zhang L. Galectin-3 contributes to vascular fibrosis in monocrotaline-induced pulmonary arterial hypertension rat model. J Biochem Mol Toxicol. 2017; 31(5).

[13] He J, Li X, Luo H, Li T, Zhao L, Qi Q, Liu Y, $\mathrm{Yu}$ Z. Galectin-3 mediates the pulmonary arterial hypertension-induced right ventricular remodeling through interacting with NADPH oxidase 4. J Am Soc Hypertens. 2017; 11(5): 275-289.e2.

[14] Hao M, Li M, Li W. Galectin-3 inhibition ameliorates hypoxia-induced pulmonary artery hypertension. Mol Med Rep. 2017; 15(1):160168.

[15] Calvier L, Legchenko E, Grimm L, Sallmon H, Hatch A, Plouffe BD, et al. Galectin-3 and aldosterone as potential tandem biomarkers in pulmonary arterial hypertension. Heart. 2016; 102(5): 390-6.
[16] Berezin AE. Endothelial progenitor cells dysfunction and impaired tissue reparation: The missed link in diabetes mellitus development. Diabetes Metab Syndr. 2017; 11(3):215-220

[17] Berezin AE. Prognostication in Different Heart Failure Phenotypes: The Role of Circulating Biomarkers. J Circ Biomark. 2016; 5:6. doi: 10.5772/62797.

[18] Fenster BE, Lasalvia L, Schroeder JD, Smyser J, Silveira LJ, Buckner JK, et al. Galectin-3 levels are associated with right ventricular functional and morphologic changes in pulmonary arterial hypertension. Heart Vessels. 2016; 31(6):939-46.

[19] Mazurek JA, Horne BD, Saeed W, Sardar MR, Zolty R. Galectin-3 Levels Are Elevated and Predictive of Mortality in Pulmonary Hypertension. Heart Lung Circ. 2017; 26(11):1208-1215.

[20] Berezin AE. Metabolomics in Heart Failure Patients: Hype and Hope J. Biomarkers. 2016; 2 (3): 21-23.

Citation: Alexander Berezin. Is Galectin-3 a Prognosticator of Severity and Clinical Outcomes of Pulmonary Artery Hypertension?. ARC Journal of Cardiology. 2018; 4(1) 15-17. doi: dx.doi.org/11.20431/24555991.0401005.

Copyright: () 2018Authors. This is an open-access article distributed under the terms of the Creative Commons Attribution License, which permits unrestricted use, distribution, and reproduction in any medium, provided the original author and source are credited. 